\title{
Employees' Predispositions to Routinised Work: Measurement Issues
}

\author{
Grażyna Wieczorkowska-Wierzbińska* \& Wojciech Karczewski**
}

\begin{abstract}
Summary
We dream of a job that makes us most productive, comfortable and satisfied. But often we focus on salary, job status and ignore the mismatch between job requirements and our psychophysiological predisposition. In the long run can pay the high costs of the mismatch, so the measurement of employees' psychophysiological predispositions is a crucial problem. In the first part of the paper we examine the definition of basic concepts: the job's predisposition and degree of work routinization. The second part of the paper addresses the problems of questionnaire measurement on example of 3 questionnaires: NEOFFI, SSA, Gallup's Clifton StrengthsFinder Assessment. In the empirical part we present the results of measurement of the 2 predispositions (METICULOUSNESS and ADAPTABILITY) important for prediction psychophysiological costs in performing the highly routinized work. The analyses of the data $(\mathrm{N}=1132$ employees of different corporations +4748 colleagues of theirs) have shown: (1) the necessity of eliminating distortions related to the response style by data ipsatization; (2) the significant differences in ADAPTABILITY and METICULOUSNESS between self vs. other -descriptions; (3) the negative relationship between ADAPTABILITY and METICULOUSNESS scores.
\end{abstract}

Keywords: Job routinization, NEO-FFI, Gallup's Clifton StrengthsFinder Assessment

JEL: M12, C12, C18

\section{INTRODUCTION: PROBLEMS WITH CONCEPTS DEFINITION}

The development of management science is based on progress achieved in the basic sciences: economy, psychology, law, and sociology. Similarly to medicine, which has its roots in biology, chemistry, physics, as well as in psychology, management science generates new research questions stimulating the advancements of disciplines fundamental to it.

Management is said to be a discipline of knowledge and practice, hence - just like in medicine - the diagnosis should play a fundamental role. The problem of the diagnosis is important to the extent that the subject of our research is complex organisms which, contrary to inanimate objects, are characterised by possible opposite reactions to stressor. Stress factors for people or organisations may cause either negative or positive (enhancing) effects. The most interesting is antifragility (Taleb, $2012)=$ property of systems that means an increase in ability to resist (robustness) or recover from failure (resilience).

Some believe that every scientific work should begin from providing precise definitions of the terms "proceduralised work" and "predispositions". The definition of a term(Formal concept) requires the specification of the conditions necessary and sufficient for a given object to be recognised as an example of the concept. Let us illustrate this on the example of a square, defined as a geometric figure that meets two conditions: [w1] has 4 equal sides, and [w2] 4 90-degree angles. The first condition is necessary but not sufficient. All squares meet this condition but so do rhombuses, thus, it is not a sufficient condition. All squares fit the w1 and w2 conditions, and no nonsquares fit both of them. So using a formal concept of SQUARE we have only 2 degrees of belongings of exemplars: 1 for all squares and 0 for all nonsquares.

\footnotetext{
* Faculty of Management, University of Warsaw, Poland, https://orcid.org/0000-0002-3307-1679

** Faculty of Management, University of Warsaw, Poland, https://orcid.org/0000-0002-0672-7513
} 
In social sciences and in everyday life we don't use formal concepts but natural ones (categories) that cannot be defined with equal precision. Natural concepts are described by the most typical exemplar called a prototype.

Even concept SQUARE is used by people in everyday life as a natural one. We can categorize shapes of carpets using more than 2 values by saying that one carpet is more SQUARE like than the other, but the third one cannot be described as a square. So using a natural concept of SQUARE we have more degrees of belongings of exemplars. We can say that carpet \#1 is more SQUARE like (degree of belonging $=0.8$ ) than the carpet \#2 (degree of belonging $=0.6$ ) other, but the third one cannot be described as a square (degree of belonging $=0$ ). The prototype of a natural concept of a square is a figure that meets both formal requirements. Different object can be more or less different from the prototype.

Analogically we have a prototype of proceduralised work (with the highest degree of routinisation) is assembly line work, where every movement of the worker is precisely programmed. Different jobs can be compared with this prototype.

\section{DEGREE OF ROUTINISATION OF WORK}

As we said before we can not specify precise conditions for work to be considered as proceduralised ${ }^{1}$ or not (2 values), but we can compare different jobs on the dimension of routinisation.

Procedures often describe sequences of actions that the employee has no right to change. Processes with a medium degree of routinisation are applied in project management methodologies and good practice collections (e.g., PMBOK, Prince2, and ITIL). Work with a low degree of proceduralisation/routinisation is usually mentioned in the context of organisations operating in a very unstable environment, often requiring unforeseen actions to be taken e.g., consulting companies, hospitals, and law firms (Pava, 1983). Such work requires solving problems that are unstructured (to a greater or lesser extent).

The performance of simple procedures may lead to an unpleasant monotony. If excitation evoked by monotonous stimuli exceeds a certain level, it is switched to inhibition, which also leads to extending the response time and weakening vigilance. Drowsiness is an example of the protective inhibition of the cerebral cortex caused by monotonous stimuli. The monotony level of work is comprised of both the characteristics of the environment and the work process. On the other hand, repetitive elements can give a pleasant "rest". At this point, it is also worth calling to mind studies (Monahan, Murphy \& Zajonc, 2000) comparing the impact of a single exposure of 25 stimuli with the fivefold exposure of 5 stimuli. They demonstrated that repeating stimulation gives rise to a temporary generalised improvement of the affective state. This study may explain the positive impact of that meditation, the recitation of litanies, or listening to song choruses has on our mind. The repetition of both sounds and movements gives rise to a relaxation response. Moreover, this also explains the positive impact of music and dance on our wellbeing.

Carrying out procedures may also have a similar effect. Some employees actually prefer the stabilisation and security associated with them not having to make decisions concerning their work. Some prefer routines, repetition, and specific and set out methods of work rather than change, diversity or decision-making. Other employees, on the other hand, have more satisfaction from being able to decide about their duties. In our studies where three groups of employees with higher education were asked if they find chaos, too much information, or monotony more tiring, most respondents $[55 \%, 77 \%$, and $54 \%$, respectively] pointed to monotony as being more tedious.

\footnotetext{
Similarly much time has been spent on vain attempts to precisely define motivation, personality, and leadership.
} 
Decisions concerning what, how, and in which order we do things are constantly being made by us. What time we are going to have Sunday lunch, when we are going to do the cleaning, go shopping, or our next holiday destination.... Some people simplify their lives by repeating the same decisions and sequences of actions, while others keep on starting over. Routinised (simplified and implemented) action schemata require much less energy than continually discovering new and previously unknown solutions (Pleskac \&Werhsbale, 2014). A measure of the individual propensity for developing and implementing routine choices in life is important as it allows us to gain a better understanding of (Gersick \& Hackman, 1990; Weick, 1979) and to better predict the adaptation process to the organisational routines imposed on employees (Laureiro-Martinez, 2014).

\section{PREDISPOSITIONS}

When assessing potential employees, we use various different terms: ability, skill, qualifications, competences, predispositions, and preferences. We make inferences about qualifications based on past achievements, whereas, when it comes to competences, we emphasise the prediction of future achievements. Abilities designate the speed of learning - some people master instruments more quickly, others mathematics, and still others master a dance choreographic movement sequence faster than others do. Thanks to practice, persons of different abilities may NOT differ in terms of their skills, although the less talented are unlikely to become masters in their art but can still be excellent in their craft. We still know too little about the genetic determinants of the differences in predispositions, but epigenetics shows how important the influence of the environment is on gene expression. The easiest way to become a murderer is if conducive factors, both of a biological and environmental nature, appear at the same time.

Having predispositions to perform a certain type of work means that our properties allow us to carry out this job with lower psychological costs than those incurred by mismatched persons. Predispositions can also include biologically determined temperament properties such as reactivity, defined as the relation of the strength of reaction to the strength of the stimulus, resistance to being overburdened, and the need for various types of stimulation - motor, intellectual, social, etc. It is on their basis that individual differences in processing information and organising actions are shaped. The former are referred to as cognitive styles or thinking styles, the latter as styles of action. As it is difficult to separate behaviour from our thoughts, thus, it is justified to talk of cognitive behavioural styles or styles of activeness.

One of the dimensions of a point working style (Wieczorkowska, 1992; Wieczorkowska \& Burnstein, 1999) is a fondness for routinisation, which may be an indicator of good work organisation but also be a necessity resulting from lower energy levels designated by temperament.

\section{QUESTIONNAIRE METHODS OF THE MEASUREMENT OF PREDISPOSITIONS}

The well-known expression of Gordon Allport: "If you want to know something about a person, why not first ask him?", triggered a plethora of different self-descriptive techniques measuring a variety of psychological traits. The internet is also a place where we can find many professional companies offering such diagnoses.

One such example is the popular questionnaire rooted in the Five-Factor Model of Personality that was developed on the basis of lexical studies. The short version of the NEO-FFI inventory contains 60 questions allowing a respondent to be described in terms of 5 dimensions: neuroticism, extraversion, openness to experience, agreeableness, and conscientiousness. Theoretically, we can try to predict the predispositions of an employee to proceduralised work on the level of their personality 
- using the responses to questions in the openness to experience and conscientiousness scales. People with low results in the openness to experience scale and scoring high in conscientiousness should feel more comfortable with proceduralised work. The NEO-FFI questionnaire consists of first-person singular imperative sentences, which may be problematic if the respondent lacks the relevant experience. Taking, for example, the sentence stating "I often try new and exotic meals", it may be negated by both those who do not like novelty and those who would like to experiment with exotic meals but have not yet had the chance to. However, the biggest problem is the lack of uniformity of both theoretical constructs. In the set measuring openness to experience, as many as $1 / 4$ of the questions concern interests in art/poetry. "Conscientiousness", another scale of the NEO-FFI, entails both the need for achievements and responsibility, and pedantry. This lack of heterogeneity makes it difficult to imagine a person who would obtain a high/low result on the scale. Allport had already pointed this problem out, stating that the factors obtained in the analysis are dimensions of an averaged personality that is completely abstract, and of no use to a psychologist wanting to probe the personality of specific persons. It is difficult to reject a questionnaire measure until a better method of measurement is found, but we do have to bear in mind that when measuring the properties of persons using tests similar to the NEO-FFI, we are tearing apart the relationship with the behavioural observation level, and are analysing statistical abstracts. The proponents of such a method of measurement will argue that the NEO-FFI scales have high reliability (homogeneity) indexes measured using Cronbach's alpha, forgetting that it fails to guarantee the single-factoredness of scales. It is very easy to obtain a high alpha if we take a sufficiently large number of nonnegatively correlated questions.

Apart from questionnaires containing single sentences/questions, there are also tools available that require the person being diagnosed to select one of two options. There is, by way of example, the Survey on Styles of Activity (SSA) made up of items comprising opposing descriptions of the behaviours of two persons: $\mathrm{A}$ and $\mathrm{B}$, and the following questions: "Would your behaviour/feelings in this situation be more similar to A, mostly to A, to B, or mostly to B?" The respondent can also choose the "It's difficult to say" response, which is treated as the mid-point on the scale.

This way of formulating questions seems to have undeniable advantages because high/low results are obtained by respondents who point to person $\mathrm{A}$ in half of the items, and to person $\mathrm{B}$ in the rest of the items, which eliminates the effects of the tendency towards acquiescence. What is important is that SSA questions are directly related to the organisation of actions, thanks to which it is very easy to imagine the behaviour of a person who has obtained high/low results on the scale.

Information about somebody different, person $\mathrm{A}$, or person $\mathrm{B}$, behaving in a certain way somehow legitimises this behaviour, which weakens the effect of the social approval variable. One difficulty in phrasing questions containing binary choices is the fact that not all interesting aspects can be presented in the form of a simple alternative.

The main SSA psychometric requirement was for the developed scales to meet measurement model assumptions, thus, mainly for them to be single-factor, even at the cost of a substantial reduction in the number of questions.

\section{LIMITATION OF QUESTIONNAIRE TECHNIQUES}

When creating various questionnaire tools, we forget that it has already been demonstrated in a series of studies that we are often unconscious of the influences to which we succumb, however, this does not stop us from being convinced that we are perfectly capable of accurately pointing to the reasons behind our thoughts, feelings, and behaviours. Self-descriptions refer to knowledge about the Self. For some people, their responses to questionnaire questions result from their deliberations 
on the matter, while for others, who have never spared a thought about it, their responses are created "on-line". We differ in terms of our abilities and our propensity to self-reflect, alike, and it is these differences that affect the measurement accuracy. We can go through life without any insight into the mechanisms underpinning our behaviours. Looking at ourselves introspectively, from the point of view of a detached observer, to many of us, unfortunately, seems to be an artificial and completely unnecessary task. In effect, we are unaware of the defence mechanisms that distort our Self-image. We perceive others much more accurately.

Exactly how useful the analysis of self-descriptions is depends on many factors. Responses may be relatively more reliable if questions refer to overt attitudes and the person being diagnosed is not interested in making a good impression, is motivated to gain insight into their own predispositions, and has the propensity to self-reflect and self-observe. Persons allowing themselves to be diagnosed, often creating their own image, present themselves in such a way as to protect their self-esteem and meet the perceived expectations of the employer.

Another example is questionnaires measuring emotional intelligence through self-description. Self-descriptive techniques concerning emotional abilities can be compared to the questions being asked in a school intelligence test, that is: "Do you think that you're intelligent?". Task-oriented evaluations of intelligence evoke much more trust in us. The only problem is that, although it is easy to test mathematical abilities, emotional abilities are mainly manifest in the use of contextual information, mainly non-verbal communication, which are not even supplied by audiovisual tools, not mentioning questionnaires based on verbal communication.

\section{IMPORTANCE OF RESPONSE STYLE TO QUESTIONS}

In the study described in detail in the doctoral dissertation of Karczewski (2019) employees from different corporations responded ${ }^{1}$ to 102 self-descriptive questions and provided the e-mail addresses of at least 3 colleagues who know them well and who agreed to provide some information about them by answering the same questions. After the data cleaning procedure described in the doctoral dissertation, the subject of analysis were the responses of 1132 (44\% male) persons being diagnosed and of $\mathbf{4 7 4 8}$ colleagues of theirs.

The theoretical framework for the measurement was Gallup's Clifton StrengthsFinder assessment, based on the premise that 5 characteristic talents can be identified for each employee. The 177-item questionnaire measuring 34 talents was developed in the 1980s by Donald O. Clifton and his former student M. Buckingham. The copyrights to it were purchased by the Gallup Institute, which maintains on its website that over 20 million persons have so far received the talent assessments. The 102-item instrument based on Gallup's Clifton StrengthsFinder assessment is available on the Polish market.

The subject of our analysis is the indicators of two "talents": meticulousness (discipline in Gallup's wording) and adaptability, each built on the basis of the responses to 3 questions. The scale of responses depends on whether the questions were answered by the person who was assessing themselves (focus: SELF) or by the person who was assessing their colleague (focus: he/she).

Tables 1 and 2 show the distribution of responses from the point of view of each of the groups:

They were asked not to spend more than 10 seconds on each question. 
Table 1. METICULOUSNESS: distribution of responses to relevant questions for the self-description (focus: SELF) and for the description of colleagues (focus: he/she)

\begin{tabular}{|c|c|c|c|c|c|c|}
\hline \multirow[b]{2}{*}{ Answer } & \multicolumn{2}{|c|}{$\begin{array}{c}\text { Frequently pay attention } \\
\text { to detail }\end{array}$} & \multicolumn{2}{|c|}{$\begin{array}{l}\text { I like creating detailed } \\
\text { action plans }\end{array}$} & \multicolumn{2}{|c|}{$\begin{array}{l}\text { I often think: This has to be put } \\
\text { in order, the actions have to be } \\
\text { planned step-by-step }\end{array}$} \\
\hline & Self & he/she & Self & he/she & Self & he/she \\
\hline 1 & 18.4 & 20.0 & 14.9 & 24.0 & 17.0 & 34.4 \\
\hline 2 & 43.8 & 40.0 & 38.3 & 39.5 & 52.2 & 48.3 \\
\hline 3 & 23.1 & 23.6 & 24.6 & 20.9 & 20.3 & 10.5 \\
\hline 4 & 12.7 & 14.7 & 18.1 & 13.4 & 9.0 & 5.6 \\
\hline 5 & 1.9 & 1.7 & 4.1 & 2.3 & 1.5 & 1.2 \\
\hline
\end{tabular}

Response scale:

For SELF: 1 - Strongly describes me, 2 - Describes me well, 3 - Neither yes, nor no, 4 - Doesn't describe me, 5 - Doesn't describe me at all

For him/her: 1 - Strongly describes them, 2 - Describes them well, 3 - Neither yes, nor no, 4 - Doesn't describe them, 5 - Doesn't describe them at all

Table 2. ADAPTABILITY: distribution of responses to relevant questions for the self-description (focus: SELF) and for the description of colleagues (focus: he/she)

\begin{tabular}{|c|c|c|c|c|c|c|}
\hline \multirow[b]{2}{*}{ Answer } & \multicolumn{2}{|c|}{$\begin{array}{l}\text { I easily adapt to changing } \\
\text { circumstances }\end{array}$} & \multicolumn{2}{|c|}{$\begin{array}{l}\text { I like doing many things at } \\
\text { once - I'm inspired by new } \\
\text { circumstances }\end{array}$} & \multicolumn{2}{|c|}{$\begin{array}{l}\text { New circumstances are there to } \\
\text { adjust to them - I always treat } \\
\text { change as something natural }\end{array}$} \\
\hline & Self & he/she & Self & he/she & Self & he/she \\
\hline 1 & 26.7 & 27.1 & 19.0 & 18.4 & 22.7 & 20.9 \\
\hline 2 & 49.7 & 47.2 & 42.6 & 39.6 & 54.5 & 48.1 \\
\hline 3 & 16.3 & 15.5 & 21.1 & 24.4 & 16.4 & 19.6 \\
\hline 4 & 6.8 & 9.2 & 14.2 & 15.3 & 6.0 & 10.1 \\
\hline 5 & 0.5 & 1.0 & 3.1 & 2.2 & 0.4 & 1.3 \\
\hline
\end{tabular}

Response scale:

For SELF: 1 - Strongly describes me 2 - Describes me well 3 - Neither yes, nor no, 4 - Doesn't describe me, 5 - Doesn't describe me at all For him/her: 1 - Strongly describes them, 2 - Describes them well, 3 - Neither yes, nor no, 4 - Doesn't describe them, 5 - Doesn't describe them at all

The responses to the above questions allow indicators to be built and (it would seem) for talents to be diagnosed. Unfortunately, such a standard analysis fails to factor in the respondent response style, which distorts the results.

We forget that the responses of the respondents to the questions posed are not always the result of the transformation of the inner assessment into the response scale prepared by the researcher. In order to answer closed-ended questions, the respondent has to transpose their "private" assessment into the response scale supplied by the researchers, for example: two, three, five, seven-... point (see Figure 1). 
Figure 1. Sample response scales for closed-ended questions. The deprived of content response of "Difficult to say" should be placed at the end of the scale but then it is often recoded into a median value

\begin{tabular}{|l|l|l|l|l|l|l|}
\hline 1 & 2 & 3 & 4 & 5 & 6 & \\
\hline $\begin{array}{l}\text { Strongly } \\
\text { agree }\end{array}$ & agree & $\begin{array}{l}\text { Slightly } \\
\text { agree }\end{array}$ & $\begin{array}{l}\text { Slightly } \\
\text { disagree }\end{array}$ & disagree & $\begin{array}{l}\text { Strongly } \\
\text { disagree }\end{array}$ & $\begin{array}{l}\text { Difficult } \\
\text { to say }\end{array}$ \\
\hline
\end{tabular}

\begin{tabular}{|l|l|l|l|l|}
\hline 1 & 2 & 3 & 4 & \\
\hline $\begin{array}{l}\text { Strongly } \\
\text { agree }\end{array}$ & agree & disagree & $\begin{array}{l}\text { Strongly } \\
\text { disagree }\end{array}$ & $\begin{array}{l}\text { Difficult } \\
\text { to say }\end{array}$ \\
\hline
\end{tabular}

\begin{tabular}{|l|l|l|}
\hline 1 & 2 & \\
\hline agree & disagree & $\begin{array}{l}\text { Difficult } \\
\text { to say }\end{array}$ \\
\hline
\end{tabular}

\begin{tabular}{|l|l|}
\hline 1 & 2 \\
\hline agree & disagree \\
\hline
\end{tabular}

Are the persons responding to closed-ended questions not at all bothered about the response scale prepared for them by the investigator? Of course not! We asked the respondents to rank 6 possible response scales for a specific question, ranging from: their MOST preferred (ranked as 1) to their LEAST preferred (ranked as 6).

As we expected, there were different preferences even in such a homogenous sample as University of Warsaw students. A 7-point scale that includes a midpoint and an available "don't know" response was selected as the most preferred scale by almost $\mathbf{3 5 \%}$, and as the least preferred by over $26 \%$. A 2-point scale was chosen as the most preferred by almost $16 \%$, and as the least preferred by over $\mathbf{4 8 \%}$. Preferences with regard to the response scale may depend on the types of questions being put, but also be a characteristic of the respondent, in other words, depend slightly on the object that is currently being assessed. We can then speak of a response STYLE.

The transformation of the inner opinion into a scale with only two responses may be the most difficult. These appeal to respondents inclined to perceive the world dichotomically (which may but does not have to be linked to a lower level of education), and to those who consider the question matter of little importance. Dichotomous questions are not well received by "cognitively complex" respondents who feel forced to choose between two extremes, which do not give across their views fully. That is when they usually get discouraged from responding to questions phrased in this way. Researchers often include a midpoint on the scale ("Slightly agree/disagree", "neither agree nor disagree", etc.), which provides an escape from assuming an opinion. Research has shown that the absence of a midpoint answer does not increase the number of responses that are devoid of content, hence, its inclusion on the scale is pointless.

A respondent's answers may be affected by the need for social approval, manifest in the tendency to use positive response categories (acquiescence response style), or, on the contrary, the need to present oneself as being nonconformist, expressed in the tendency to use negative response categories (dis acquiescence response style) (Harzing, 2006). Some only pick the extremes 
of a response scale (extreme response style), which may be interpreted as having an intolerance of ambiguity or a sign of more weakly articulated cognitive structures. Extreme responses concern important, emotionally engaging objects. Failing to take the response style differences into account may lead to distorted findings, which has been demonstrated in comparative studies of Polish and German teenagers (Wieczorkowska \& Smoleńska, 1993), response comparisons of Italian and Japanese respondents in ISSP surveys (Wieczorkowska, Wierzbiński \& Kuźmińska, 2013), and in marketing research alike (Baumgartner \& Steenkamp, 2001).

\section{NECESSITY OF IPSATIZATION}

There is no reason to assume that the responses to survey questions were not distorted by the response style of the person answering the question. In order to factor in the "use of the response scale" by the responding person, the simplest transformation is the IPSATIZATION of results, in other words, presenting the responses to the questions posed in the form of distances from a set point on a scale and the mean from the responses to all the questions.

To illustrate this, let us compare raw and ipsatised results of two respondents: Eve and Adam, who obtained the following results on the meticulousness and adaptability scale

\begin{tabular}{ccc}
\hline raw results & Meticulousness & Adaptability \\
\hline Eve & 2 & 3 \\
Adam & 5 & 4 \\
\hline
\end{tabular}

When comparing the raw numbers on the scale, we will find that Adam is both more orderly (his score is higher on the meticulousness dimension) and more flexible (his score is higher on the adaptability dimension) than Eve. If, however, we calculate that they used the response scale differently because the mean response to 102 questions for Eve was 2.5, and came to 4.5 for Adam, hen,

\begin{tabular}{cccc}
\hline raw results & meticulousness & adaptability & average use of scale \\
\hline Eve & $2-2.5=\mathbf{- 0 . 5}$ & $3-2.5=\mathbf{0 . 5}$ & 2.5 \\
Adam & $5-4.5=\mathbf{0 . 5}$ & $4-4.5=\mathbf{- 0 . 5}$ & 4.5 \\
\hline
\end{tabular}

comparing the ipsatised results, we will say that Adam is more orderly but less flexible than Eve.

In the studies described by Karczewski, the average of the responses to the 102 questions was calculated and named the SCALE indicator. The dominant tendency was "ascribing the possession of talents, since the self-descriptions averaged $3.74(\mathrm{~s}=0.3 \mathrm{~N}=1132)$. The colleague description average was even higher.

Figure 2 below presents the distributions for this indicator, showing considerable interpersonal differentiation in the way the response scale was used (for the lower $10 \%$, the average was smaller than 3.36 , for the upper $10 \%$, it was greater than 4.11 ). 
Figure 2.

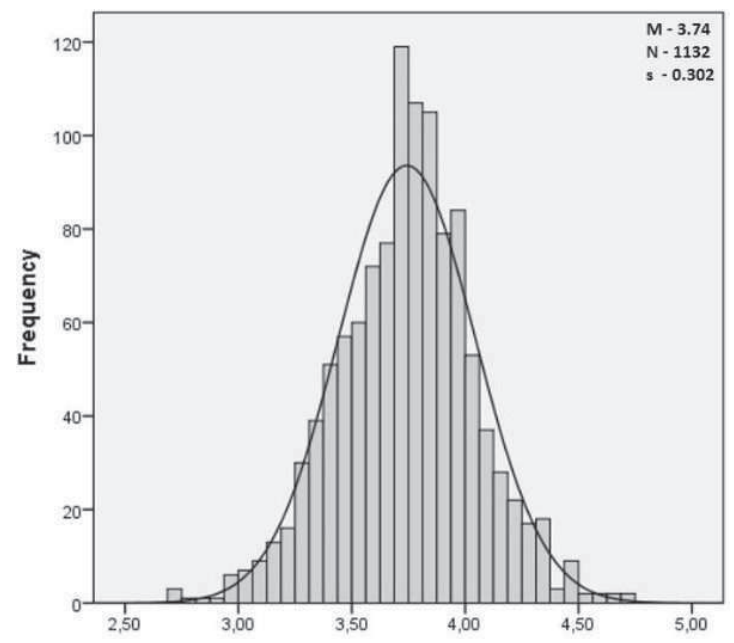

Let us now compare the distributions, Cronbach's alphas, and correlation coefficients between the two indicators created for

- $\quad$ self-descriptions $\mathrm{N}=1132$

- colleague descriptions $\mathrm{N}=4748$

The doctoral dissertation of Karczewski also presented analyses after the aggregation of the object of assessment (average rating of at least 3 colleagues $\mathrm{N}=1132$ ), but this issue was omitted from it due to the volume limitations.

A comparison of the results of both these indicators (raw values vs ipsatised values) reveals that the variable is "more continuous" after ipsatisation, meaning that it accepts more values, which is not, by any means, of trivial significance when we want to divide the group according to positional measures (see ordered distributions - figures 3-6, the distributions for adaptability look similar).

The release of values of the METICULOUSNESS and ADAPTABILITY indicators from the effect of the response style gave rise to a higher degree of correlation of questions creating the same factor indicated by Cronbach's alpha (see Table 4).

Figure 3. Meticulousness - self-descriptions (after ipsatiZation)

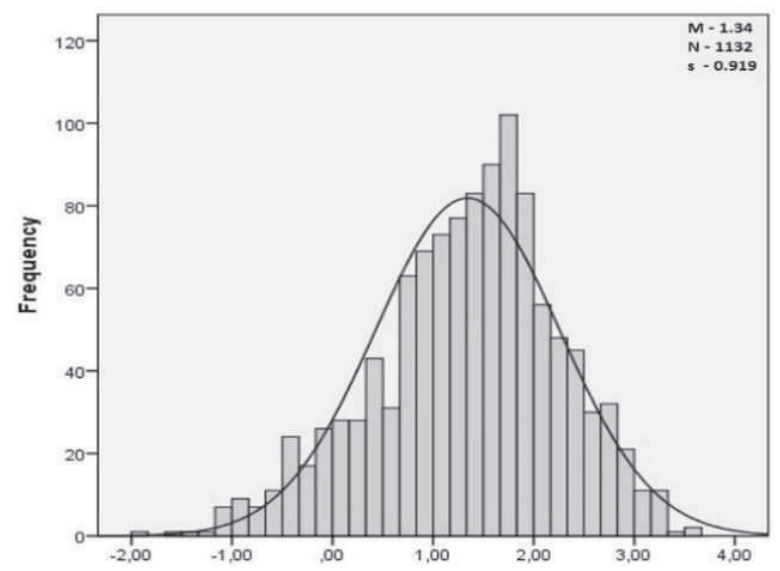

Figure 4. Meticulousness - colleague descriptions (after ipsatiZation)

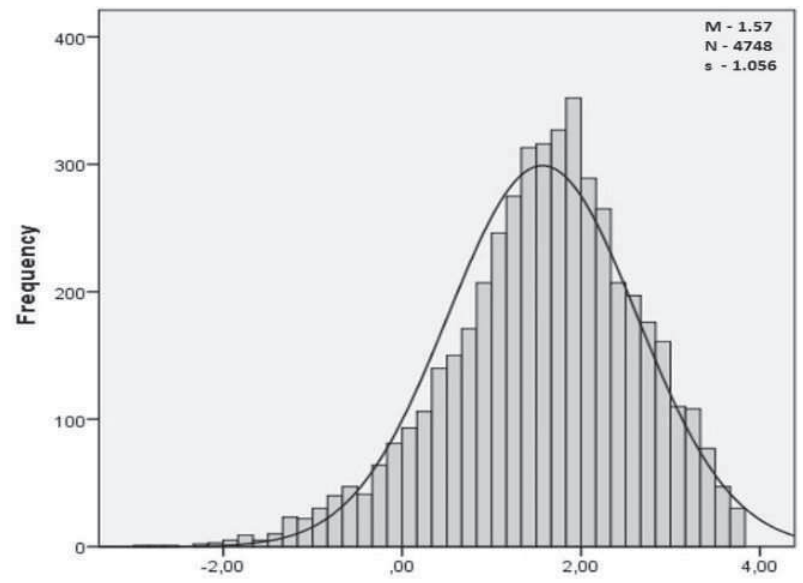


Figure 5. Meticulousness - self-descriptions (before ipsatiZation)

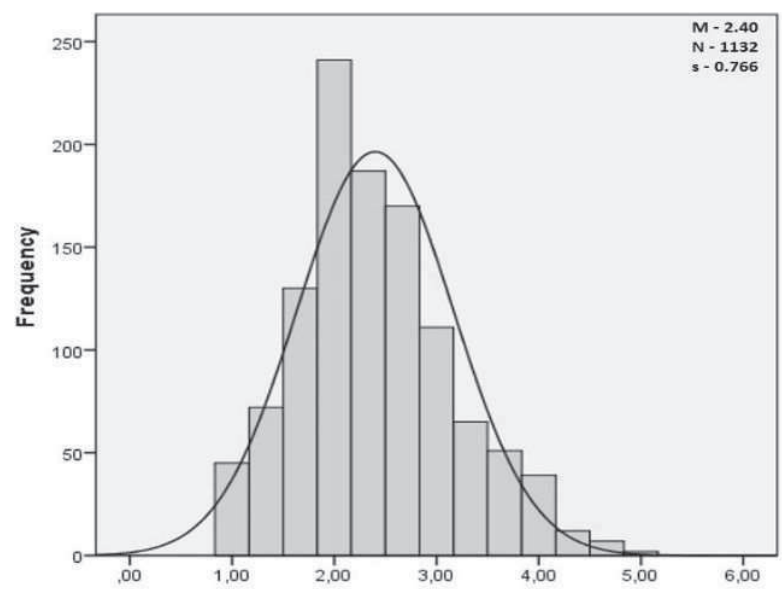

Figure 6. Meticulousness - colleague descriptions (before ipsatiZation)

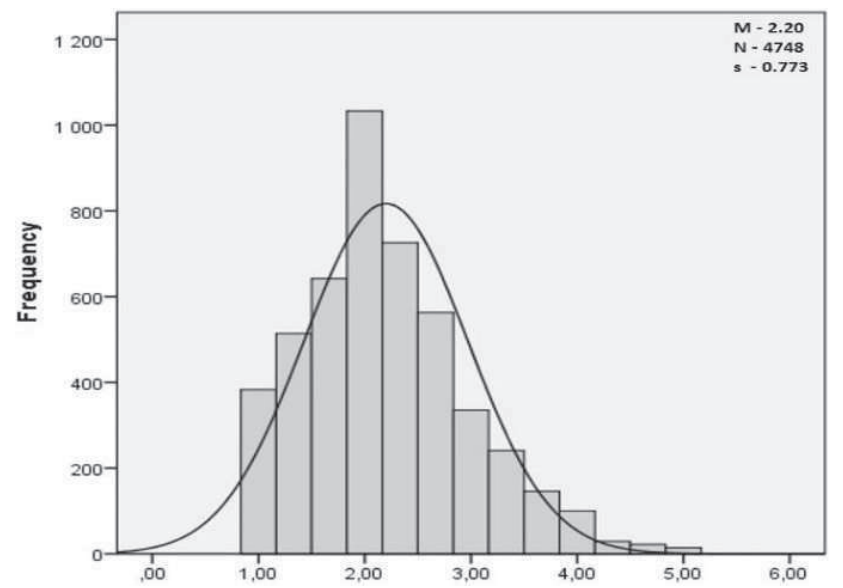

Table 4. The effect of ipsatization on Cronbach's alpha for both scales

\begin{tabular}{llcc}
\hline \multicolumn{1}{c}{ assessment dimension } & \multicolumn{1}{c}{$\begin{array}{c}\text { data } \\
\text { type }\end{array}$} & $\begin{array}{c}\text { self-description } \\
\mathrm{N}=1132\end{array}$ & $\begin{array}{c}\text { colleague description } \\
\mathrm{N}=4748\end{array}$ \\
\hline $\begin{array}{l}\text { ADAPTABILITY } \\
3 \text { questions }\end{array}$ & $\mathrm{Raw}$ & 0.644 & 0.713 \\
\hline & after ipsatization & 0.781 & 0.852 \\
\hline $\begin{array}{l}\text { METICULOUSNESS } \\
\text { questions }\end{array}$ & Raw & 0.671 & 0.689 \\
\cline { 2 - 4 } & after ipsatization & 0.771 & 0.833 \\
\hline
\end{tabular}

The most important difference, however, concerns the correlation between the two "talents". According to the theory, we could predict that the focus on meticulousness may reduce adaptability, which seems to confirm the not very high but significantly negative correlation coefficient for selfdescriptions $r=-0.101$. However, already in the colleague assessments, all the "talents" are positively correlated with the remaining talents. Seeing the significantly positive correlation coefficient of $r=+0.16$, we could conclude that meticulousness is conducive to adaptability.

The ipsatisation of results, on the other hand, gives us unequivocal conclusions that are also consistent with the theory (see Table 5)

Table 5. The correlation coefficient between meticulousness and adaptability (all coefficients are statistically significant)

\begin{tabular}{lcc}
\hline data type & $\begin{array}{c}\text { self-description } \\
\mathrm{N}=1132\end{array}$ & $\begin{array}{c}\text { colleague description } \\
\mathrm{N}=4748\end{array}$ \\
\hline Raw & -0.101 & 0.16 \\
after ipsatisation & -0.357 & -0.263 \\
\hline
\end{tabular}

Conclusion - in order for Gallup's diagnosis of talents performed on over 20 million employees to be to used in further research, the results should be freed from the distorting impact of the 
"response style". The rank results for an individual will not change - the ipsatization of 34 talents is a linear transformation and, therefore, it retains the rank order of raw data. It is, however, necessary if we want to compare, for instance, the talents of two employees.

\section{NON-QUESTIONNAIRE METHODS OF MEASUREMENT OF PREDISPOSITIONS}

It can be presumed that psychometric instruments based on self-description turned out to be a blind alley in science, as evidenced by the absence of any progress in psychometry in recent decades, but we must remember that although self-description is a highly imperfect measurement tool, it is, however, better than no instrument at all.

Measurement flaws are a problem that disqualifies our results only if we fail to see them. If we are aware of the inevitable distortions that our self-descriptions are subject to, we can take steps to make appropriate adjustments.

A subtler method of diagnosis could be analysing the non-verbal indicators like facial expressions, body movements, or changes in the way a person speaks, or the continuous capture of physiological measurements throughout the performance of various types of tasks. Such observations may be valuable because, compared to self-description: many non-verbal behaviours are less subject to conscious control and censorship. Non-verbal behaviours can be measured without turning the attention of the person being diagnosed to that fact that measurements are being taken.

We have to remember, however, that:

Physiological measurements, like the heart rate, and the galvanic skin response, are indicators of the general level of arousal, without differentiating between the types. New possibilities that are provided by neuroimaging do not yet allow for its mass application.

The comparison of non-verbal reactions of various people does not make much sense because the interpersonal differences are very large in this extent. The non-verbal expressions of some people are very limited but very vivid for others. Comparisons can be made only "within a person", similarly to polygraph tests where the recording of physiological changes are not compared to any external "standards", just to the differences "within a person" when they give TRUE or FALSE responses to questions with a known and unknown correct answer. Knowing the recording of physiological reactions accompanying these answers that are characteristic of a given person, we can try to predict when a person is lying. Computer software can now monitor the pupil size and alert us once the vigilance of the person being monitored falls.

When observing a respondent completing a questionnaire, we can sometimes notice signs of mental/emotional withdrawal: "What stupid questions these are! How much more of this is there?". This is an indicator of low involvement, which indicates a low level of psychological realism, and it poses a greater threat to the accuracy of diagnoses than a low situational realism ${ }^{1}$. That is why the use of diagnostic games is so valuable, where everything that is happening is real, important, and affects our thoughts, feelings, and behaviours. In this setting nobody can say that they are bored any more.

A series of tasks were developed at the Department of Managerial Psychology and Sociology during which several things are measured, e.g. resistance to boredom and distractors, speed of differentiation, level of concentration under time and or pressure. We should remember, however, that a diagnosis of predispositions should not be based on a single outcome but on the speed of learning and the subjective evaluation of psychological costs involved in carrying out a given type of task.

\footnotetext{
Situational (mundane) realism refers to the extent to which the experimental situation is similar to situations people are likely to encounter outside of the laboratory. Psychological (experimental) realism is the extent to which situations created in social psychology experiments are real and impactful to participants (compare: Aronson \& Wieczorkowska, 2001).
} 
If our goal is, for instance, to diagnose the ability to categorise, so vital in times of an excessive choice of products and information, the speed at which a person masters it is imperative. It is also important to remember that our behaviour changes depending on whether we are playing against a computer or another person. Repeatedly replicated studies using the "ULIMATUM" game requiring the acceptance or rejection of the proposal to share $\$ 10$ between players have shown that we will accept any amount, no matter how small, from a computer but only an amount that is considered as "fair" from a person. The neuroimaging studies of the players demonstrated that the low offers given by a person activate areas "responsible for" negative emotions. The stronger the stimulation of this area, compared to the area involved in the "pursuit of goals", the greater the probability of rejection of such an offer. These dependencies were not found when it came to playing against a computer. It follows from this that it is worth introducing interactions with other people to diagnostic games, even in the form of a simulation of a conversation through a communicator.

\section{SUMMARY}

Just like the breakthrough in medicine came not through new theories but through the advancement of technology, so too will be the case when it comes to management science. All that remains is to wait patiently, working intensely with the tools currently available to us. A good diagnostic instrument can help us gain a greater self-awareness of our predispositions and, in so doing, better understand the costs incurred by us when doing our work. There are professions that can be carried out only in point (Wieczorkowska, 1992) form: sequentially and precisely, such as that of a surgeon or a pharmacist. In other professions, like journalism, different action styles may give equally good results. Sometimes different elements of complex works require different predispositions. In the work of a professor, both introverts and extraverts are awarded bonuses. Can it be presumed that a diagnosed propensity for routinisation is an indication to choose proceduralised work? Reluctance to routinisation in employment in the liberal professions as well as teleworking may end with a motivational paralysis. Writers waiting for inspiration or attempting to write several books at once vs those that sit down to write every day at a set time are a good example for the analysis of the consequences of how well-matched a person is. The lack of external restrictions in liberal professions requires self-meticulousness, thus, the ability to establish routines is extremely valuable. A moderately ill-match of predispositions/preferences to the environmental requirements may stimulate development, while a completely ill match is tantamount to stagnation. Another thing worth keeping in mind is that significant bonuses and penalties may modify the action style. Experimental studies have shown that respondents can adjust their behaviour to the instructions to exercise greater or less precision in carrying out a command. However, the differences appear on the level of the subjectively assessed costs by them. The effectiveness of a style of action depends both on the environmental requirements and on the energy capacity set out by temperament. Not being well-matched results in overload, which is manifest in a lower wellbeing on the emotional and cognitive level alike.

Therefore, the way we do our work does not depend solely on what we like. Oftentimes we have no choice. It is estimated that only $20 \%$ of the sellers of advanced technologies actually like having contacts with clients. Employee predispositions/preferences were taken into account in one of the sales firms where sellers were having 2 to 3 meetings per week with clients. Instead of settling accounts with employees separately, they work in a team. This allows those sellers who like having contact with people to carry out many more meetings with clients, leaving the two other sellers to prepare the meeting documentation and any new offers. This is a positive example of how an accurate diagnosis of employee predispositions has led to the reorganisation of work in a manner that enhanced both employee productivity and satisfaction. 


\section{Literature}

Aronson, E., \& Wieczorkowska, G. (2001). Kontrola naszych myśli i uczuć. Warszawa: Santorski.

Baumgartner, H., \& Steenkamp, J. B. (2001). Response Styles in Marketing Research: A Cross-National Investigation. Journal of Marketing Research, 38(2), 143-156, https://doi.org/10.1509/jmkr.38.2.143.18840.

Gersick, C. J., Hackman, R. J. (1990). Habitual routines in task-performing groups. Organizational Behavior and Human Decision Processes, 47(1), 65-97, https://doi.org/10.1016/0749-5978(90)90047-D.

Harzing, A. W. (2006). Response Styles in Cross-national Survey Research: 26-country Study. International Journal of Cross Cultural Management, 6(2), 243-266, http://dx.doi.org/10.1177/1470595806066332.

Karczewski, W. (2019). Predyspozycje do wykonywania pracy wysoko zrutynizowanej. Rekomendacje dla zarzadzania zasobami ludzkimi (Unpublished doctoral dissertation) Warszawa: University of Warsaw.

Laureiro-Martinez, D. (2014). Cognitive Control Capabilities, Routinization Propensity and Decision Making Performance. Organization Science, 25(4), 1111-1133, https://doi.org/10.1287/orsc.2014.0899.

Monahan, J. L., Murphy, S. T., Zajonc, R. B. (2000). Subliminal mere exposure: Specific, general, and diffuse effects. Psychological Science, 11(6), 462-466, https://doi.org/10.1111/1467-9280.00289.

Pava, C.H.P. (1983). Designing managerial and professional work for high performance: A sociotechnical approach. National Productivity Review, 2(2), 126-135, https://doi.org/10.1002/npr.4040020204.

Pleskac, T. J., \& Wershbale, A. (2014). Making assessments while taking repeated risks: A pattern of multiple response pathways. Journal of Experimental Psychology: General, 143(1), 142-162, http://dx.doi.org/10.1037/ a0031106.

Weick, K. E. (1979). The social psychology of organizing. New York: McGraw-Hill

Wieczorkowska, G., \& Smoleńska, M. Z. (1993). Kryteria wartościowania u młodzieży w latach 1985-1990. Psychologia Wychowawcza, 2, 122-131.

Wieczorkowska, G., \& Burnstein, E. (1999). Adapting to the transition from Socialism to Capitalism in Poland: The Role of Search Costs and Screening Strategies in Social Change. Psychological Science, 10(2), 98-105, https://doi.org/10.1111/1467-9280.00115.

Wieczorkowska-Siarkiewicz, G. (1992). Punktowe i przedziatowe reprezentacje celu. Uwarunkowania i konsekwencje. Warszawa: University of Warsaw.

Wieczorkowska-Wierzbińska, G., Wierzbiński, J., \& Kuźmińska, A. (2014). Porównywalność danych sondażowych zebranych w różnych krajach. Psychologia Społeczna, 2(29), 128-143, doi: 10.7366/1896180020142901. 